\title{
O mar e os pescadores ou a ténue fronteira entre a realidade e a ficção no cinema de Leitão de Barros
}

\author{
Sérgio Bordalo e Sá \\ Instituto de Etnomusicologia - centro de estudos em música e dança / \\ polo da Faculdade de Motricidade Humana da Universidade de Lisboa, Portugal
}

\begin{abstract}
José Leitão de Barros is an unavoidable name of the Portuguese cinema from the 20s to the 50s. Despite having worked during a dictatorship, one can see in his films traces of an authorship mark that go beyond the ties of the regime. One of these marks is a coherent universe that passes through several films. During his career, he has directed five movies that have the sea and fishermen as its main theme: Nazaré, Praia de Pescadores (1929), Maria do Mar (1930), A Pesca do Atum (1939), Póvoa de Varzim (1942) e Ala-Arriba! (1942). At first sight, we could think that this set of films had a similar structure: two documentary short films of a particular location (Nazaré, Praia de Pescadores e Póvoa de Varzim) would frame two feature films made shortly after in those same locations with the participation of the local population (Maria do Mar e Ala-Arriba!). However, this is not the case as we intend to show how A Pesca do Atum is more a preamble, or a preparatory study for Ala-Arriba! than Póvoa de Varzim itself. We will also focus on the strong documental aspect even of the feature films, which is not a surprise as, according to José Manuel Costa, Leitão de Barros was in line with the international trend of the 20s that inspired the origin of documentary as a film genre.
\end{abstract}

Keywords: Leitão de Barros, Estado Novo, Auteur Theory, Documentary, Film Genre

\section{Introdução}

Na filmografia de José Leitão de Barros, as fronteiras entre a ficção e a não-ficção aparecerem por vezes esbatidas. Um desses casos ocorre num conjunto de cinco filmes feitos num intervalo de 13 anos, durante a primeira metade da sua carreira, que têm o mar e os pescadores como tema dominante: Nazaré, Praia de Pescadores (1929), Maria do Mar (1930), A Pesca do Atum (1939), Póvoa de Varzim (1942) e Ala-Arriba! (1942). A forte vertente documental manifesta em todos eles não é de estranhar, visto que, segundo José Manuel Costa, Leitão de Barros esteve em consonância com a base inspiradora da origem do documentário como género cinematográfico. ${ }^{1}$ À primeira vista, somos levados a pensar que este conjunto de filmes teria uma estrutura semelhante: duas curtas-metragens documentais de uma determinada localidade (Nazaré, Praia de Pescadores e Póvoa de Varzim) enquadrariam dois filmes de ficção realizados nessas mesmas localidades com a participação da população local (Maria do Mar e Ala-Arriba!). No entanto, como iremos ver, não será bem assim, já que podemos considerar mais $A$ Pesca do Atum como o preâmbulo, ou estudo preparatório para Ala-Arriba! do que propriamente Póvoa de Varzim.

\section{O mar e os pescadores como recorrência temática}

Havendo uma série de elementos que se repetem, permitimo-nos agrupar estes filmes numa determinada categoria temática. Iremos enumerar esses elementos para depois os tratar mais em pormenor individualmente: o mais evidente deles é a presença do mar durante praticamente todo o tempo, constituindo-se ele próprio como uma personagem que influencia (e de que maneira) as restantes; o mercado como importante espaço de interacção entre quem participa no filme; a manutenção da tradição verifica-se na aparição de crianças vestidas com roupas de pescadores e igualmente no respeito pelos mais velhos nos conselhos de anciãos, onde se decidem questões relevantes dentro da comunidade; e finalmente a rede de pesca que, sendo um elemento comum a todas as personagens, encontra ainda um uso mais unificador quando se torna a "rede da noiva". Se quisermos ir um pouco mais além, poderemos acrescentar que o esforço físico do trabalho da pesca é visto de dentro dos próprios barcos, nomeadamente quando os homens estão a remar, e podemos resumir o argumento dos dois filmes de ficção (Maria do Mar e Ala-Arriba!) numa só frase: uma história de amor entre duas pessoas de famílias desavindas, uma espécie de variação sobre o mito de Romeu e Julieta e também de Amor de Perdição, de Camilo Castelo Branco.

A imagem do mar torna-se emblemática em todos estes filmes logo nas respectivas cenas iniciais: em Nazaré, Praia de Pescadores, a câmara começa por estar fixa quando o vemos, mas depois acompanha formalmente o desvendar da vila ao espectador com um travelling frontal a partir do ponto de vista do comboio, "encosta acima", como refere o intertítulo narrativo. Quando se chega à "Ponta do Milagre", uma panorâmica dá-nos a ver o "largo presépio branco até ao mar", para voltarmos a um travelling frontal a partir do comboio nos "três minutos até à praia" desde a encosta, ou seja, a câmara de Leitão de Barros movimenta-se mimetizando a nossa deslocação até à vila. O mesmo sucede em A Pesca do Atum e Póvoa de Varzim, com um travelling de um barco no mar sobre as rochas no primeiro caso e panorâmicas sobre a praia e a vila no segundo. Ao invés, em Maria do Mar e Ala-Arriba!, as imagens iniciais do mar são a partir de câmara fixa. $O$ espectador sente-se transportado para os sítios nas curtas-metragens documentais, enquanto nas longas-metragens de ficção o estatismo inicial da câmara nos impõe a presença do lugar, tudo maioritariamente através da imagética do mar. Notase uma clara influência das vanguardas da época (especialmente soviética) em Leitão de Barros nos primeiros planos de Maria do Mar, em que podemos 
ver as casas da vila de Nazaré filmadas de uma forma quase cubista. $^{3}$

Voltando a Nazaré, Praia de Pescadores, um intertítulo diz-nos que "de manhãzinha, as ruas são painéis medievais", com crianças a brincarem, mulheres a deslocarem-se "e o mercado nos dias bons tem de tudo". As pessoas estão nas compras, mas a câmara ainda provoca espanto, com muitas delas, especialmente as crianças, a olharem directamente para ela, algo que já não se vê 13 anos depois em Póvoa de Varzim, em cujo mercado na praça central as mulheres vão comprando vários tipos de coisas, mas passando a câmara mais despercebida. De qualquer maneira, a presença do mercado é comum aos dois filmes, constituindo-se como o ponto de encontro dos seus habitantes, permitindo às mulheres adquirirem artigos para as lides domésticas e às crianças brincarem. Em Maria do Mar, o mercado funciona como expiação do suicídio do pai por parte de Maria: "morto o pai, Maria trabalha no campo" "e vende no mercado de Leiria", dizem os intertítulos, sendo o mercado apresentado em vários planos e estando cheio de pessoas. O trabalho funciona também para se limpar a mente e mostrar que a vida continua, apesar dos reveses.

"Desde pequeninos, eles e elas se vestem como os pais" e a tradição da pesca começa desta maneira a passar de pais para filhos, estando as crianças na praia e apresentando pormenores da roupa dos pescadores. Esta sequência de Nazaré, Praia de Pescadores tem eco em Maria do Mar, cuja imagem das crianças a brincar na praia surge logo a seguir ao suicídio do arrais Falacha, antecedida pelo intertítulo "nasceram novas manhãs" e seguida de "e novas vidas para o mar": as crianças são encaminhadas logo em pequenas para a vida de pescador e são elas que asseguram a continuação da actividade, aprendendo desde cedo a conviver com o perigo que Ihe é inerente. Este lado trágico confere ao universo de Leitão de Barros uma especial singularidade, rara no cinema nacional, porventura a antecipar Nazaré (1952) de Manuel Guimarães.

Em Nazaré, Praia de Pescadores, encontramos intertítulos como "quando os entendidos dizem que o mar está bom, partem barcos para o mar", temos um plano de dois pescadores mais velhos a falarem e um grande plano de outro: a sua decisão é dada no plano seguinte, quando vemos o mar com os barcos de pesca ao fundo. Já em Ala-Arriba!, a presença dos anciãos, marca da importância do passado, é mais formal, dado que são "juízes" que vão tratar das "partilhas de rede" na sequência da não-realização do casamento entre João Moço e Julha, por este a ter traído com uma cigana. "Agora vão intervir os juízes, os homens de respeito" e a sua importância é realçada pelo uso do contrapicado numa panorâmica para os mostrar. ${ }^{4} \mathrm{Na}$ parte final do filme, e depois de João ter demonstrado a sua valentia ao salvar Augusto Bô, o pai de Julha, de morrer afogado, são também eles que tornam a ir a casa dos pais de João, dizendo-lhes para voltarem a aceitar o filho, que tinha sido expulso de casa. Cada um deles expõe as suas razões em três planos americanos separados, reforçando o destaque e a importância que tinham na comunidade: o plano americano confere-lhe autonomia e proeminência. ${ }^{5}$

A rede de pesca é outro elemento comum aos três filmes e tem mais do que um significado, porém, a sua função principal é naturalmente simbolizar o trabalho e o esforço que a pesca requer. Em Nazaré, Praia de Pescadores, "o nascimento da rede" é demonstrado por dois grandes planos de um rapaz e um adulto a construírem-na ("como uma enorme renda, carinhosamente se guarda a rede"), havendo vários homens na praia a vigiá-la. Manuel e Maria já estão juntos em Maria do Mar, apesar da forte oposição das respectivas mães, quando vemos pescadores a lançarem as redes ao mar, porque "o mar... deu o pão de cada dia." Graças ao que a rede apanha, a sua vida pode ser feita em conjunto e esta sequência antecede a do nascimento da filha, que vai permitir no final a reconciliação das mães. N' A Pesca do Atum, a rede é uma personagem por si só, já que desempenha papel decisivo na captura do peixe, sendo a magnitude do seu tamanho bem visível durante todo o filme e tendo de ter vários homens a puxá-la para o atum vir à superfície. Finalmente em Ala-Arriba!, a rede adquire o valor simbólico de representar a união entre João Moço e Julha Bô, a "rede da noiva", e é benzida com vinho para depois os noivos serem envoltos nela para "dar sorte", aquando da celebração do noivado. Para além disso, está igualmente presente noutras sequências importantes: Chibanta dá uma dourada a Ti Carminda e a Julha, que estão a consertá-la, enquanto aconselha Julha a casar com João Moço por fazerem os dois parte da mesma "igualha", segundo as suas próprias palavras; Ti Augusto está a fazer uma rede, quando a mulher, Ti Carminda, Ihe vem dizer com quem é que a filha está "a conversar"; os pescadores estão a colocar as redes no barco que vai para o mar, quando João Moço e Chibanta trocam acusações; e, como já vimos anteriormente, a rede simboliza igualmente as "partilhas" decididas pelos "juízes" aquando da anulação do casamento.

Todos estes filmes demonstram uma notória admiração pelos pescadores e a câmara de Leitão de Barros tenta estar o mais perto possível deles. $\mathrm{Na}$ última sequência conhecida de Nazaré, Praia de Pescadores (já que só a primeira bobina do filme sobreviveu até aos nossos dias), vários rapazes vão para o mar e o espectador também entra no barco com eles: vemos pormenores dos remos e posteriormente o esforço de remar. Esse vigor também resulta muito visível em Ala-Arriba!, em que os "lanchões" e os "sardinheiros" podem constituir dois tipos de classe de pescadores, mas assemelham-se perante o espectador quando estão na pesca, nomeadamente na "solidariedade poveira", que determina esperarem sempre pelo barco que vem atrás quando entram na barra. Mais tarde, surge a cena crucial do naufrágio e o salvamento de Ti Augusto por João Moço, em que aquele tinha ordenado aos seus homens para voltarem para trás a fim de ajudarem um barco em dificuldades. N' A Pesca do Atum, acompanhamos a captura do peixe igualmente dentro dos barcos onde estão os pescadores. 


\section{A iminência da tragédia como superação do conflito derivado do diferente estatuto social}

Finalmente, somos confrontados com o facto de 0 argumento das duas longas-metragens ser muito semelhante: um rapaz e uma rapariga estão apaixonados, mas as respectivas famílias têm grandes objecções ao casamento, principalmente por causa da sua diferente proveniência. Em Maria do Mar, a mãe de Maria não perdoa o facto de o marido ter morrido por causa de um engano do arrais do barco, Falacha, o pai de Manuel. A mãe deste não desculpa a mãe de Maria, por aquela ter chamado "assassino" ao marido, o que juntamente com as culpas que ele sentia por causa do naufrágio, acabaram por levá-lo ao suicídio. O que no fundo está aqui em questão, se bem que de forma transversa, é uma relação laboral que teve uma resolução trágica para ambas as partes, porque tanto o "chefe" como o "empregado" acabaram por morrer. Tia Aurélia, a mãe de Maria do Mar, diz mesmo ao arrais Falacha que foi a sua "ambição" que fez com que o barco naufragasse. Nem o casamento dos filhos, nem o nascimento da neta demove as duas mulheres. É o funeral de uma criança da idade da neta que as faz mudar de posição. Num certo sentido, a morte fá-las retornar à vida (de mães e de avós).

Em Ala-Arriba!, esta questão da diferença familiar e social ainda é mais pronunciada: é muito evidente desde início que João e Julha pertencem a dois estratos sociais diferentes, respectivamente os "sardinheiros" e os "lanchões" (variação curiosa e de cariz social sobre os Capuletos e Montequios de Romeu e Julieta). A mãe de Julha, Ti Carminda, opõe-se à união, porque a filha deveria arranjar alguém da "igualha" dela. Por outro lado, os dois pais encontram-se para combinar o casamento, que só é possível com a ascensão de João Moço a "sardinheiro", passando ele a pescar no barco de Ti Augusto Bô, o pai de Julha. Com a intromissão da cigana e o desfazer do noivado, tem que haver partilhas entre as duas famílias, partilhas essas que são aceites por Saramago, pai de João Moço, que inclusivamente expulsa o filho de casa.

Outra característica que se repete nas duas histórias é o facto de um salvamento constituir o elemento decisivo para a união dos dois casais. Em Maria do Mar, é ele que propicia o encontro entre Manuel e Maria, já que aquele a salva de morrer afogada, em sequência de elevado cariz erótico. Apesar de Manuel dizer a Maria, mais tarde quando se encontram na fonte, que "há muito que olho para ti, sem nunca chegar à fala!", agarrando-lhe posteriormente as mãos, o início do relacionamento acontece efectivamente com o salvamento e nem a objecção das mães o consegue impedir.

Em Ala-Arriba!, esse relacionamento já existia e tinha sido quebrado, quando o salvamento do pai de Julha por parte de João Moço lhe permite retomar definitivamente o seu lugar e fazer com que a comunidade piscatória desculpe de vez o desvio de João Moço com a cigana, desvio esse que já tinha sido perdoado pela própria Julha. No entanto, sem a concordância dos restantes pescadores, o equilíbrio tornava-se muito difícil e, portanto, o resgate faz com que João Moço volte a ser acolhido pela comunidade, possibilitando a reunião do par amoroso.

Este erotismo na representação do corpo humano é algo que diferencia Leitão de Barros de outros realizadores seus contemporâneos. Luís de Pina considera que o modo como o corpo humano é filmado em Maria do Mar revela a "audácia" e a "modernidade" de Leitão de Barros, e permite-lhe ultrapassar as fronteiras de uma história convencional. ${ }^{6}$ Mesmo num documentário como Pesca do Atum, Leitão de Barros não se coíbe de apresentar o corpo humano sob diferentes pontos de vista, com o objectivo de o realçar. Por último, retomamos a questão de Póvoa de Varzim não ser bem um preâmbulo de Ala-Arriba!, como Nazaré, Praia de Pescadores o é de Maria do Mar. Em relação a estes dois, a associação resulta pacífica. O primeiro passa-se fundamentalmente na praia da Nazaré, fazendo o enquadramento da vila no cenário, através da chegada por comboio e dos planos gerais a partir da encosta, e a caracterização dos seus habitantes, seja no mercado, seja principalmente enquanto pescadores (na primeira parte do filme, a única disponível, vemo-los a preparar os barcos e as redes para a pesca). Mesmo os tempos de "ócio" são passados no paredão da praia, pelo que o mar é quase sempre omnipresente. Maria do Mar como que se aproveita desse filme como introdução (e esboço) para se abster de fazer mais explanações, já que os planos iniciais da Nazaré, mostrando as casas, a praia e o mar, são curtos e muito escassos. Para além disso, as cenas mais relevantes do filme são passadas na praia: é no mar que, obviamente, se dá o naufrágio do barco do arrais Falacha e é também no mar que Manuel salva Maria de morrer afogada. ${ }^{7}$ Ou seja, o que Nazaré, Praia de Pescadores começa por mostrar é desenvolvido em Maria do Mar, que lhe acrescenta a componente ficcional (ou dramática) da história, mas mantendo a participação da comunidade local.

Se repararmos bem, o mesmo não se passa em relação a Póvoa de Varzim e Ala-Arriba! Aquele está menos relacionado com a especificidade da actividade piscatória, do que com o desenvolvimento industrial e a modernização da vila. Temos naturalmente os planos iniciais que a enquadram, com uma panorâmica sobre a praia e outra sobre a vila, aos quais se juntam vários encadeamentos de imagens desta. Na praça, as mulheres também andam nas compras, mas as semelhanças com Nazaré, Praia de Pescadores ficam por aqui. Deste ponto em diante, Leitão de Barros mostra-nos as indústrias que proliferam na vila: mulheres trabalham numa fábrica de conservas de sardinha, outras estão numa de tecelagem, homens fabricam cordas para os barcos e "A Poveira" é uma fábrica de tecidos de algodão, cuja saída das trabalhadoras leva Leitão de Barros a fazer um plano muito semelhante ao plano fundador dos irmãos Lumière. ${ }^{8}$ Mas não é só o desenvolvimento industrial o único ponto de interesse na Póvoa de Varzim, vemos igualmente uma praça de touros, com o público a aplaudir, o "Diana Bar" cheio de clientes e o casino, igualmente lotado. Há um certo tom cosmopolita 
nestas imagens que se afasta inevitavelmente do carácter mais tradicional da pesca. Pretendia-se dar, já em 1942, uma ideia da modernização de Portugal levada a cabo pelo regime. Neste sentido, é que se pode considerar A Pesca do Atum como o antecessor de Ala-Arriba!, já que o esforço feito pelos pescadores daquele para apanhar atum tem eco no esforço desenvolvido pelos pescadores deste quando os barcos chegam à barra. Há portanto uma relação transposta e complexa entre as curtas-metragens e o seu desenvolvimento ficcional nas longas-metragens, ou seja, estamos perante uma obra coerente que se vai construindo e aprimorando ao longo de cada filme, o que constitui a marca autoral de Leitão de Barros.

\section{Conclusão}

Partindo destes pressupostos, podemos considerar que o 'estilo pessoal' de Leitão de Barros é manifesto em inúmeros aspectos da sua obra, nomeadamente em dois planos muitos semelhantes em Maria do Mar e Ala-Arriba! Quando o mar está demasiado agitado, os sinos da igreja tocam e a população vai toda a correr para a praia a rezar para que os barcos de pescadores cheguem em segurança. Em ambos os filmes, Leitão de Barros utiliza o mesmo plano geral, que segundo Roberto Nobre "Eisenstein não desdenharia" (Nobre 1964, 126), para mostrar a massa humana a correr pelo areal abaixo. Este plano permite não só ter uma visão completa da dimensão da população, mas também reduzi-la à sua insignificância (vistas assim de longe, as pessoas parecem autênticas formigas) de nada poder fazer perante o poderio do mar. $\mathrm{E}$ o que é facto é que em ambos os filmes há pescadores que morrem. O que parece ser uma deriva funciona aqui como evidência da diversidade e complexidade do universo de Leitão de Barros, não fazendo da sua abordagem ao mundo piscatório uma mera pesquisa folclórica, mas a marca da sua grandeza estética e do seu valor autoral.

\section{Nota Finais}

"Acreditando que o documentário pode ser visto como um movimento histórico preciso com gestação e identidade próprias, um movimento que não se identifica com a «inocência dos pioneiros» e que, ao invés disso, foi já um movimento de reacção, gerado no cadinho das vanguardas de 20 e na transição para os anos 30 , há que sublinhar, antes de mais, que até houve em Portugal alguns exemplos sintonizados com o que se pode considerar a base inspiradora dele. Todas as obras de Leitão de Barros daquele período de viragem de década (Nazaré, Praia de Pescadores, de 1929, Lisboa, Crónica Anedótica, de 1930, ou até mesmo, em parte Maria do Mar, também de 1930, em alguns dos seus aspectos) (...) partilharam esse contexto de mudança em que o documentário se formou" (Costa 2001, 17).

${ }^{2}$ Todas as frases entre aspas referem-se aos intertítulos do filme.

${ }^{3}$ Novamente a influência de Eisenstein manifesta na rapidez da montagem e nos planos quebrados da própria arquitectura dos edifícios, mas também ecos de Dovjenko e das vanguardas francesas, de Marcel d'Herbier a Jean Epstein.

${ }^{4}$ Segundo Marcel Martin, "o plano contrapicado (...) dá em geral uma impressão de superioridade, de exaltação e de triunfo, porque engrandece os indivíduos e tende a magnificálos, recortando-os no céu até os envolver numa auréola de neblina" (Martin 2005, 51).
${ }^{5}$ De acordo com Franz Weyergans, no plano americano "os seus [das personagens] rostos dominam, os seus gestos são facilmente perceptíveis e tomam uma significação imediata" (Weyergans 1971, 20-21).

6 "Leitão de Barros manifesta também a sua audácia e a sua modernidade (...) no modo como revelou sensualmente os corpos e como insinuou um claro erotismo em algumas cenas (o pai afagando os seios da filha, o pescador quase nu trazendo a rapariga nua sob o vestido molhado, a recortarIhe as formas, o banho das jovens perto da foz), dando aos comportamentos uma outra verdade e uma motivação mais intensa: o convencionalismo da história desaparece ante a força anímica das relações humanas" (Pina 1986, 65).

${ }^{7}$ Foi preciso chegar ao Mudar de Vida (1966), de Paulo Rocha, para haver um filme de ficção ambientado no mar sem naufrágios.

${ }^{8}$ La Sortie de l'Usine Lumière à Lyon (1895).

\section{Bibliografia}

Acciaiuoli, Margarida. 2003. "Vida e Obra de Leitão de Barros" - depoimento. In Ala-Arriba! De Leitão de Barros. Portugal: Madragoa Filmes. DVD.

Bazin, André. 2001. "De la politique des auteurs" in Cahiers du Cinéma, n 70, avril 1957. In La Politique des Auteurs - Les Textes. Editado por Antoine De Baecque, 99-117. Paris: Cahiers du Cinéma.

Costa, José Manuel. 2001. “Questões do Documentário em Portugal" in Clareira no Caminho das Estrelas, Uma - Olhar Sobre uma Década de Documentário Português. Amascultura - XII Encontros Internacionais de Cinema Documental.

De Baecque, Antoine, ed. 2001. La Politique des Auteurs - Les Textes. Paris: Cahiers du Cinéma.

Ferro, António. s.d. [1931] Hollywood, Capital das Imagens. Lisboa: Portugal-Brasil.

Kael, Pauline. 1963. "Circles and Squares" in Film Quarterly, vol. XVI, n³, spring 1963, 12-26.

Lopes-Ribeiro, António. 1982. "Retrato tirado pelo natural". In J. Leitão de Barros. Organizado por José de Matos-Cruz, 8-9. Lisboa: Cinemateca Portuguesa.

Martin, Marcel. 2005. A Linguagem Cinematográfica. Lisboa: Dinalivro.

Matos-Cruz, José de, org. 1982. J. Leitão de Barros. Lisboa: Cinemateca Portuguesa.

Nobre, Roberto. 1964. Singularidades do Cinema Português. Lisboa, Portugália Editora.

Pais, José M. 1990. "Austeridade e moralismo dos padrões estéticos". In Portugal Contemporâneo, vol. IV (1926-1958). Dirigido por António Reis, 349-352. Lisboa: Publicações Alfa.

Pina, Luís de. 1986. História do Cinema Português. Mem Martins: Publicações Europa-América.

Ramos, Jorge Leitão. 2004. "O cinema salazarista" in História de Portugal, vol. XVI - O «Estado Novo» (II). Dirigido por João Medina, 323-356. Alfragide: SAPE.

Sarris, Andrew. 1970. "Notes on the Auteur Theory in 1970" in Film Comment, vol. 6, n 3, Autumn 1970: 6-9.

Sarris, Andrew. 1971. "Notes on the Auteur Theory in 1962" in Film Culture - An Anthology. Editado por P. Adams Sitney, 121-135. London: Secker \& Warburg.

Sarris, Andrew. 1976. "A Theory of Film History" in Movies and Methods: An Anthology. Editado por Bill Nichols, 237-251. Berkeley: University of California Press.

Sarris, Andrew. 1977. "The Auteur Theory Revisited" in American Film, vol. II, n 9, July - August: 49-53.

Weyergans, Franz. 1971. Tu e o Cinema. Barcelos: Companhia Editora do Minho. 